\title{
Academic achievement, close up work parameters, and myopia in Singapore military conscripts
}

Seang-Mei Saw, Hui-Min Wu, Benjamin Seet, Tien-Yin Wong, Eric Yap, Kee-Seng Chia, Richard A Stone, Lionel Lee
Abstract

Aim-To determine the relation of refractive error to environmental factors, including close up work, in Singapore military conscripts.

Methods-A cross sectional study was conducted on 429 Singapore military conscripts. Non-cycloplegic refraction and A-scan biometry were performed in both eyes. A detailed questionnaire was administered by in-person interview to obtain information about current and past near work activity, extra tuition lessons, educational experiences, and family demographics.

Results-Myopia associated with the conscript having been educated in the (gifted, special, or express) educational streams fidence interval CI 2.0-7.3), and having completed pre-university education $(\mathrm{OR}=4.1,95 \%$ CI 1.9-8.8). The reported close up work activity at age 7 years did correlate with age of onset of myopia $(p<0.001)$. In parallel, supplemental tuition lessons in primary school has $(O R=2.6,95 \%$ CI 1.4-4.9) associated with conscript myopia. Parental myopia was positively associated with myopia $(p<0.001)$, but this relation disappeared when adjusted for environmental factors. Current $(p=0.83)$ and past close up work activity at age 7 years $(p=0.13)$ did not correlate with myopia.

Conclusion-Educational level and educational stream positively related to myopia. A relation was observed with reported close up work activity in early childhood and with tuition classes during elementary school, but not with current close up work activity. These results underscore the strong influence of environment in myopia pathogenesis but a role for close up work activity remains indeterminate. (Br F Ophthalmol 2001;85:855-860)

Ophthalmology, University of

Pennsylvania School of

Medicine, Scheie Eye

Institute, Philadelphia, PA 19104, USA

R A Stone

Correspondence to: Dr Seang-Mei Saw,

Department of Community, Occupational and Family Medicine, National

University of Singapore, 16

Medical Drive, Singapore

117597, Republic of

Singapore

cofsawsm@nus.edu.sg

Accepted for publication 12 February 2001

Most prominently in east Asian societies, myopia prevalence appears to be increasing among economically developed societies worldwide. ${ }^{12}$ While myopia may be viewed as resulting from a combination of genetic and environmental factors, the dramatic and sudden increases in myopia prevalence during the past century in certain societies argue strongly for a dominant environmental influence. ${ }^{34}$ The clinical literature dealing with the potential aetiology for myopia is massive but remarkable for its paucity of clear insights. (adjusted odds ratio $(O R)=3.8,95 \%$ con-

Prominent among the hypothesised myopia risk factors is a role for close up work, such as reading and related visual tasks. ${ }^{5-7}$ More advanced education is repeatedly associated with greater myopia prevalence, but it remains unclear if educational level is an independent risk factor or a surrogate for close up work or some other socioeconomic characteristic. ${ }^{8-10} \mathrm{To}$ explore these particular risk factors, we have conducted a cross sectional study relating close up work and educational achievement to measures of refractive status and ocular axial length. These environmental factors were assessed through a detailed questionnaire developed for this purpose and previously validated. Few available studies combine comprehensive close up work estimates with refractive error and biometry measurements.

This study analysed a volunteer subset of a disproportionate stratified sample of the population of young male adult conscripts in Singapore. Of young adult males conscripted into the Singapore Armed Forces, the myopia rate has progressively increased from $26 \%$ in the 1970 s to $79 \%$ in the 1990 s. $^{11-14}$ This time period of increasing myopia prevalence among males in Singapore includes the childhood of the recruits studied here. About $15 \%$ of Singapore's current military conscripts have myopia greater than -6.0 dioptres, a severity indicating a high risk in this population for myopia associated eye pathology. ${ }^{11}$

\section{Material and methods}

STUDY POPULATION

A cross sectional study (Singapore Armed Forces Myopia Study) of national servicemen enlisted in the Singapore Armed Forces was conducted in 1998 to 1999. For all male Singapore citizens, 2 years of national service are compulsory on reaching an appropriate age (usually 18-23 years). Only young Singaporean men with severe handicaps (including men who are legally blind) or with the most serious medical conditions are excluded from national service. Thus, the population of enlisted national servicemen represents almost Written informed consent was obtained from all national servicemen who participated in the study. Approval was obtained from the ethics committee, Defense Medical Research Institute (DMRI), Singapore.

Approximately $79 \%$ of the entire population of 15000 armed forces conscripts are myopic. ${ }^{11}$ Disproportionate stratified sampling was conducted whereby 889 subjects were randomly chosen from each 1.0 dioptre stratum of 


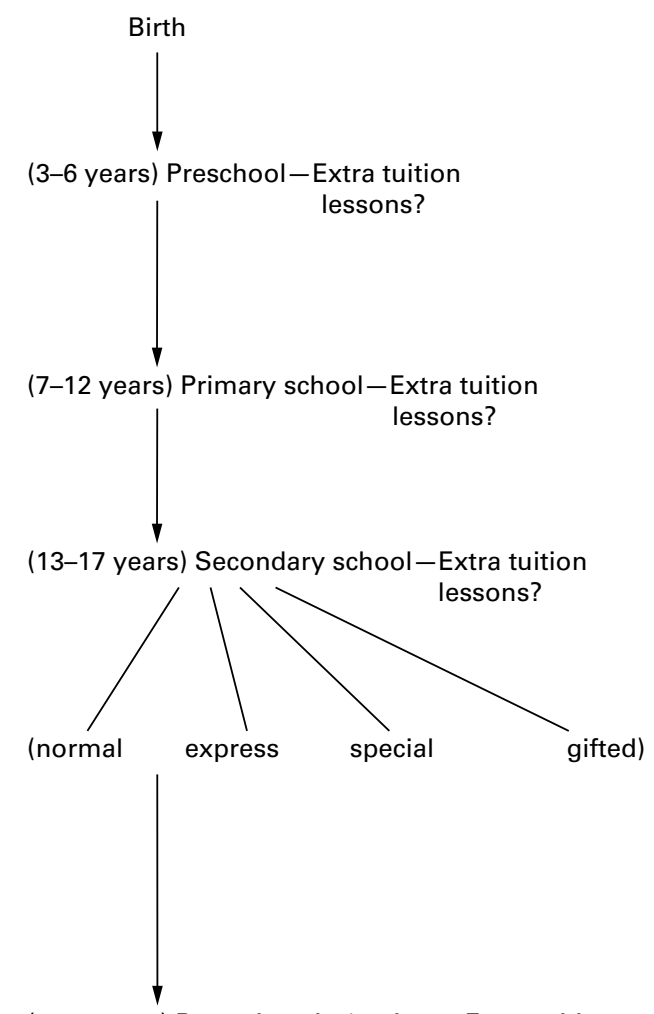

(> 17 years) Pre-university/tertiary-Extra tuition

lessons?

Figure 1 Child's schooling experience in Singapore.

spherical equivalent (SE) refractive error. This sampling technique was chosen to permit risk factor analysis in relation to both the occurrence of myopia and its severity. There were a total of 13 strata from +2.0 dioptres to -10.0 dioptres. Subjects with ocular pathology other than myopic chorioretinal degeneration were excluded. A total of 429 subjects (participation rate of $48.3 \%$ ) agreed to join the study. The mean age of the national servicemen was 21.1 years (range 19-25 years). The majority of the conscripts were Chinese $(89.6 \%)$, with the remainder being Indians, Malays, Eurasians, and other races. After completion of 4 years of secondary school (high school) in Singapore, the student joins pre-university education, which is 2 years long, before entering university (tertiary) education. In all, $54.2 \%$ of participants and $45.8 \%$ of non-participants had completed pre-university education. The mean right eye subjective refraction was -6.1 dioptres for participants compared with -5.1 dioptres for non-participants.
OCULAR MEASUREMENTS

The $\log$ MAR chart using a standard protocol was used to measure best corrected and uncorrected visual acuity in both the right and left eye. Several measures of refractive error were performed on all subjects. Myopia was measured in both eyes by full binocular subjective non-cycloplegic refraction performed by a trained optometrist. In addition, noncycloplegic refractive error measurements were made in the right and left eyes using the Nidek ARK 900 (Nidek Co Ltd, Tokyo, Japan) autorefractor and the average of six readings was obtained. Refractive error was also measured using the hand held Nikon Retinomax K-plus (Nikon Co Ltd, Tokyo, Japan) and the average of eight readings was recorded. The Pearson correlation coefficient for right eye measured by the Nidek autorefractor and subjective refraction was 0.99 and the Pearson correlation coefficient for right eye measured by the Retinomax autorefractor and subjective refraction was 0.98 . The corneal radii in the principal horizontal and vertical meridian were measured in both eyes by the Nidek autorefractor and the average of five readings in each meridian was taken. Biometry measurements of right and left eye were made using a Sonomed A 2500 A-scan ultrasound machine (Sonomed Inc, New York, USA; transducer frequency, $10 \mathrm{MHz}$ ). Axial length, vitreous chamber depth, lens thickness, and anterior chamber depth were measured. The average of five ultrasound readings was taken. The optometrists who performed the refractive error and ultrasound readings were masked to information from the questionnaire.

\section{QUESTIONNAIRE}

Both the cases and controls were interviewed at the Defense Medical Research Institute (DMRI) clinic site using the same procedures. A trained research assistant conducted the in-person interview (approximately $20 \mathrm{~min}$ utes) using a standard questionnaire. The questionnaire was translated into Chinese and the interview was conducted in either the English or Chinese language, depending on whether the recruit spoke English or Chinese.

We estimated close up work activity using several parameters. The questionnaire included quantitative information on current close up work activity (reading or writing in English or Chinese, playing video games, or computer games) on a weekday and weekend. The methods for assessment of current close

Table 1 Distribution of cylinder, biometry, and corneal curvatures measurements in the right eye for high myopes, low myopes and non-myopes among Singapore national servicemen, $1998-9(n=429)$

\begin{tabular}{|c|c|c|c|c|}
\hline & $\begin{array}{l}\text { Non-myopes (>-0.5 dioptres) } \\
(n=51)\end{array}$ & $\begin{array}{l}\text { Low myopes }(-0.5 \text { to }-5.9) \\
\text { dioptres })(n=164)\end{array}$ & $\begin{array}{l}\text { High myopes (at least }-6.0 \\
\text { dioptres) }(n=214)\end{array}$ & \multirow{2}{*}{$\begin{array}{l}\text { Two sided } p \\
\text { value }\end{array}$} \\
\hline & Median (range) & Median (range) & Median (range) & \\
\hline Cylinder (dioptres) & $0.5(0,1.5)$ & $0.5(0,3.8)$ & $1.5(0,5)$ & $<0.001$ \\
\hline Axial length (mm) & $23.4(19.8,25.4)$ & $25.4(23.0,29.4)$ & $27.3(24.9,31.5)$ & $<0.001$ \\
\hline Anterior chamber depth (mm) & $3.5(2.7,4.2)$ & $3.7(3.1,4.4)$ & $3.6(2.7,4.3)$ & $<0.001$ \\
\hline Lens thickness $(\mathrm{mm})$ & $3.8(3.4,4.4)$ & $3.7(3.3,4.3)$ & $3.8(3.2,4.6)$ & 0.007 \\
\hline Vitreous chamber depth (mm) & $16.2(12.6,18.2)$ & $18.0(15.8,21.8)$ & $19.8(17.5,24.6)$ & $<0.001$ \\
\hline Average corneal radius of curvature (mm) & $7.9(7.3,8.2)$ & $7.8(7.4,9.0)$ & $7.8(7.3,8.9)$ & 0.095 \\
\hline Axial length/corneal radius (AL/CR) ratio & $3.0(2.5,3.2)$ & $3.2(3.0,3.5)$ & $3.5(3.2,4.1)$ & $<0.001$ \\
\hline
\end{tabular}


Table 2 Characteristics of non-myopes, low myopes, and high myopes (Singapore National Servicemen 1998-9) (n=429)

\begin{tabular}{|c|c|c|c|c|}
\hline & $\begin{array}{l}\text { Non-myopes (>-0.5 dioptres) } \\
(n=51)\end{array}$ & $\begin{array}{l}\text { Low myopes }(-0.5 \text { to }-5.9 \\
\text { dioptres })(n=164)\end{array}$ & $\begin{array}{l}\text { High myopes (at least }-6.0 \\
\text { dioptres) }(n=214)\end{array}$ & \\
\hline & No $(\%)$ & No $(\%)$ & No (\%) & value \\
\hline Age of first spectacle wear (years) (median, range) & & $12(7,21)$ & $9(4,14)$ & $<0.001$ \\
\hline \multicolumn{5}{|l|}{ Father's highest educational level } \\
\hline Primary or secondary & $42(13.6)$ & $126(40.9)$ & $140(45.5)$ & 0.013 \\
\hline Pre-university or tertiary & $8(7.1)$ & $36(31.9)$ & $69(61.1)$ & \\
\hline \multicolumn{5}{|l|}{ Mother's highest education level } \\
\hline Primary or secondary & $44(14.3)$ & $144(46.8)$ & $170(55.2)$ & 0.18 \\
\hline Pre-university or tertiary & $4(7.4)$ & $17(31.5)$ & $33(61.1)$ & \\
\hline $\begin{array}{l}\text { Outdoor activity (hours per week) (median, } \\
\text { range) }\end{array}$ & $10(0,72)$ & $10(0,72)$ & $8.5(0,59.5)$ & 0.069 \\
\hline $\begin{array}{l}\text { Outdoor activity at } 7 \text { years (hours per week) } \\
\text { (median, range) }\end{array}$ & $10(0,56)$ & $8.3(0,70)$ & $7.5(0,58.5)$ & 0.16 \\
\hline \multicolumn{5}{|l|}{ Number of parents with myopia } \\
\hline None & $21(13.6)$ & $77(50.0)$ & $56(36.4)$ & $<0.001$ \\
\hline One & $11(8.3)$ & $48(36.1)$ & $74(55.6)$ & $\left(\chi^{2}\right.$ test \\
\hline Two & $4(4.8)$ & $21(25.3)$ & $58(69.9)$ & for trend) \\
\hline Unknown & $15(25.4)$ & $18(30.5)$ & $26(44.1)$ & \\
\hline
\end{tabular}

up work activity have been reported elsewhere. ${ }^{5}$ In addition to current exposure, we also asked about total close up work activity (reading and writing, computer use, and playing video games) at age 7 . Children in Singapore commence grade I at age 7 years. We ascertained whether they had extra tuition classes (either private or school) in primary or secondary school (see Appendix). We assessed academic achievement by obtaining information on the educational stream that the child entered (gifted, special, express, or normal) (Fig 1). Children in Singapore are placed in different schooling tracks (streams) based on mid year and final year grades. If the child performs well in the final primary school examinations, he or she may enter the gifted, special, or express streams. There was a strong agreement between educational level achieved and educational stream $(\mathrm{p}<0.001)$, with the children educated in the highest academic streams ultimately achieving the highest educational level.

Information on outdoor activity (hours per week) at age 7 years and in the past year was obtained. Information on parental history of myopia was obtained by asking the recruit whether the parents were wearing spectacles for short sightedness. Other questions on socioeconomic status included educational level, parent's education level, and total family income per month. We asked about the age of onset of myopia for myopic conscripts.

\section{DATA ANALYSIS}

All refractive error readings were reported as spherical equivalent (sphere + half cylinder). Data from the right eye only were analysed, as the Pearson correlation coefficient between fellow eyes was 0.98 . As the results from objective and subjective measures of refraction were very similar, only subjective refraction measurements were reported. Relevant environmental factors were compared for the three refractive error groups: high myopes (at least -6.0 dioptres), low myopes ( -5.9 to -0.5 dioptres), and non-myopes (>-0.5 dioptres). As the biometry measures confirmed the well established correlations of increasing axial and vitreous cavity lengths with increasing myopia, only the comparisons of risk factors with refractive error are detailed here. Several multivariate logistic regression models were used to determine whether the risk factors predicted myopia (yes or no), controlling for confounders. The $\mathrm{p}$ values quoted are two sided and considered statistically significant if the values are below 0.05. The data analysis was conducted using

Table 3 Tuition lessons in primary school, educational stream, and close up work activity of non-myopes, low myopes, and high myopes (Singapore national servicemen 1998-9) $(n=429)$

\begin{tabular}{|c|c|c|c|c|}
\hline & $\begin{array}{l}\text { Non-myopes }(>-0.5 \\
\text { dioptres })(n=51)\end{array}$ & $\begin{array}{l}\text { Low myopes }(-0.5 \text { to } \\
-5.9 \text { dioptres })(n=164)\end{array}$ & $\begin{array}{l}\text { High myopes (at least } \\
-6.0 \text { dioptres) }(n=214)\end{array}$ & \\
\hline & No $(\%)$ & No (\%) & No (\%) & Two sided p value \\
\hline \multicolumn{5}{|l|}{ Past activity } \\
\hline $\begin{array}{l}\text { Total close up work activity at } 7 \text { years (hours per day) } \\
\text { (median, range) }\end{array}$ & $2(0,8)$ & $2(0,10)$ & $2(0,20)$ & 0.13 \\
\hline \multicolumn{5}{|l|}{ Tuition lessons in primary school } \\
\hline Yes & $25(9.2)$ & $103(37.7)$ & $145(53.1)$ & 0.04 \\
\hline No & $26(17.0)$ & $59(38.6)$ & $68(44.4)$ & \\
\hline \multicolumn{5}{|l|}{ Tuition lessons in secondary school } \\
\hline Yes & $27(10.9)$ & $85(34.4)$ & $135(54.7)$ & 0.12 \\
\hline No & $22(12.9)$ & $73(42.7)$ & $76(44.4)$ & \\
\hline \multicolumn{5}{|l|}{ Educational stream } \\
\hline Normal & $24(22.4)$ & $45(42.1)$ & $38(35.5)$ & $<0.001$ \\
\hline Gifted/special/express & $25(8.0)$ & $114(36.5)$ & $173(55.4)$ & \\
\hline Not known & $2(20.0)$ & $5(50.0)$ & $3(30.0)$ & \\
\hline \multicolumn{5}{|l|}{ Completed educational level } \\
\hline Primary/secondary & $13(27.1)$ & $23(47.9)$ & $12(25.0)$ & $<0.001$ \\
\hline Pre-university or tertiary & $37(9.8)$ & $138(36.6)$ & $202(53.6)$ & \\
\hline \multicolumn{5}{|l|}{ Current activity } \\
\hline Total close up work activity (hours per day) (median, range) & $9.3(1.4,20.4)$ & $9.6(0.5,20.1)$ & $9.4(2.1,20.2)$ & 0.83 \\
\hline
\end{tabular}


Table 4 Adjusted odds ratios and 95\% confidence intervals for myopia (yes or no) and tuition lessons in primary school, educational stream, father's highest educational level, and education, adjusted for parental history of myopia, tuition lessons in primary school, or educational level (Singapore national servicemen 1998-9) $(n=429)$

\begin{tabular}{|c|c|c|c|c|c|c|}
\hline & $\begin{array}{l}\text { Number of } \\
\text { cases/ } \\
\text { controls }\end{array}$ & $\begin{array}{l}\text { Crude } \\
\text { odds ratio }\end{array}$ & $\begin{array}{l}\text { Adjusted odds } \\
\text { ratio }\end{array}$ & $\begin{array}{l}95 \% \text { confidence } \\
\text { interval }\end{array}$ & $\begin{array}{l}\text { Adjusted odds } \\
\text { ratio }\end{array}$ & $\begin{array}{l}95 \% \text { confidence } \\
\text { interval }\end{array}$ \\
\hline \multicolumn{7}{|c|}{ Tuition lessons in primary school } \\
\hline No & $127 / 26$ & 1.0 & 1.0 & Reference & 1.0 & Reference \\
\hline Yes & $248 / 25$ & 2.0 & 2.0 & $1.1-3.7$ & $2.6 \dagger$ & $1.4-4.9$ \\
\hline \multicolumn{7}{|l|}{ Educational stream } \\
\hline Normal & $83 / 24$ & 1.0 & 1.0 & Reference & 1.0 & Reference \\
\hline Gifted/special/express & $287 / 25$ & 3.3 & 2.8 & $1.4-5.7$ & $3.8 \ddagger$ & $2.0-7.3$ \\
\hline \multicolumn{7}{|c|}{ Father's highest educational level } \\
\hline Primary/secondary & $266 / 42$ & 1.0 & 1.0 & Reference & 1.0 & Reference \\
\hline Pre-university/tertiary & $112 / 8$ & 2.0 & 2.0 & $0.9-4.6$ & $2.2 \S$ & $1.0-5.0$ \\
\hline \multicolumn{7}{|l|}{ Educational level } \\
\hline Primary/secondary & $35 / 13$ & 1.0 & 1.0 & Reference & 1.0 & Reference \\
\hline Pre-university/tertiary & $340 / 37$ & 3.4 & 3.4 & $1.6-6.9$ & 4.19 & $1.9-8.8$ \\
\hline
\end{tabular}

*Odds ratios adjusted for parental history of myopia.

+Odds ratio of tuition lessons in primary school adjusted for parental history of myopia and education.

¥Odds ratio of educational stream adjusted for parental history of myopia and tuition lessons in primary school.

Odds ratio of father's education adjusted for parental history of myopia and tuition lessons in primary school.

$\uparrow$ Odds ratio of educational level adjusted for parental history of myopia and tuition lessons in primary school.

STATA version 5.0 (Stata Corporation, College Station, TX, USA 1995).

\section{Results}

The mean refraction was -6.2 (SD 4.2 ; range -16 to 8.3 dioptres) for the participant group. The median best corrected $\log$ MAR visual acuity was 0 (range -0.1 to 0.7 ). The median cylinder, biometry, corneal curvature radius, and $\mathrm{AL} / \mathrm{CR}$ ratio measurements were compared for the right eye in 51 non-myopes, 164 conscripts with low myopia, and 214 conscripts with high myopia (Table 1). Myopes had longer eyeballs $(\mathrm{p}<0.001)$, deeper anterior chambers $(p<0.001)$, and longer vitreous cavities $(p<0.001)$. The average corneal curvature radius was similar in high myopes, low myopes, and non-myopes $(\mathrm{p}=0.095)$. The $\mathrm{AL} / \mathrm{CR}$ ratio was highest in high myopes and lowest in nonmyopes $(\mathrm{p}<0.001)$.

We compared the socioeconomic, demographic, and lifestyle factors for myopes and

Table 5 Tuition lessons in primary school, educational stream, close up work activity and age of onset of myopia (Singapore national servicemen 1998-9)

\begin{tabular}{|c|c|c|}
\hline & Age of onset of myopia & \multirow{2}{*}{$\begin{array}{l}\text { Two sided } p \\
\text { value }\end{array}$} \\
\hline & Median, mean (SD) & \\
\hline \multicolumn{3}{|c|}{ Father's highest educational level } \\
\hline Primary/secondary & $10.0,10.2(2.9)$ & \multirow{2}{*}{0.003} \\
\hline Pre-university/tertiary & $9.0,9.2(2.7)$ & \\
\hline \multicolumn{3}{|c|}{ Mother's highest educational level } \\
\hline Primary/secondary & $10.0,10.1(2.9)$ & \multirow[t]{2}{*}{0.004} \\
\hline Pre-university/tertiary & $8.5,8.8(2.9)$ & \\
\hline \multicolumn{3}{|c|}{ Number of parents with myopia } \\
\hline None & $10.0,10.9(2.9)$ & \multirow[t]{4}{*}{$<0.001$} \\
\hline One & $10.0,9.8(2.8)$ & \\
\hline Two & $9.0,8.9(2.8)$ & \\
\hline Unknown & $9.0,9.1(2.6)$ & \\
\hline \multicolumn{3}{|l|}{ Past activity } \\
\hline \multicolumn{3}{|c|}{ Total close up work activity at 7 years } \\
\hline$=2$ hours per day & $10.0,10.3(2.8)$ & \multirow{2}{*}{0.012} \\
\hline$>2$ hours per day & $9.0,9.5(2.9)$ & \\
\hline \multicolumn{3}{|c|}{ Tuition lessons in primary school } \\
\hline Yes & $10.0,10.1(2.7)$ & \multirow[t]{2}{*}{0.13} \\
\hline No & $9.5,9.8(2.9)$ & \\
\hline \multicolumn{3}{|l|}{ Educational stream } \\
\hline Normal & $9.0,9.7(2.7)$ & \multirow[t]{2}{*}{0.019} \\
\hline Gifted/special/express & $10.0,10.5(3.3)$ & \\
\hline \multicolumn{3}{|c|}{ Completed educational level } \\
\hline Primary/secondary & $10.0,10.3(3.3)$ & \multirow[t]{2}{*}{0.39} \\
\hline Pre-university/tertiary & $10.0,9.8(2.8)$ & \\
\hline \multicolumn{3}{|l|}{ Current activity } \\
\hline \multicolumn{3}{|l|}{ Total close up work activity } \\
\hline$=9$ hours per day & $10.0,9.9(2.8)$ & \multirow{2}{*}{0.71} \\
\hline$>9$ hours per day & $10.0,9.9(2.9)$ & \\
\hline
\end{tabular}

non-myopes in Table 2. A higher proportion of high and low myopes had fathers who completed at least pre-university education $(p=0.013)$. High and low myopes were more likely to have reported two myopic parents $(\mathrm{p}<0.001)$. Even so, some $35 \%$ of the total myopic recruit population had no myopic parents. There was no difference in the proportion of Chinese among myopes and non-myopes $(p=0.74)$. Current outdoor activity and outdoor activity at age 7 years were not different for the different refractive error groups.

National servicemen with high or low myopia were more likely to have tuition lessons in primary school $(\mathrm{p}=0.04)$, were in the gifted, special, or express stream $(p<0.001)$, or to have completed pre-university or tertiary education $(\mathrm{p}<0.001)$ (Table 3). In contrast, national servicemen were not more likely to have tuition lessons in secondary school $(\mathrm{p}=0.12)$. Close up work activity before enrolment in the armed forces $(p=0.83)$ and at age 7 years $(p=0.13)$, were not different in high, low, and nonmyopes.

In Table 4, we used logistic regression analyses to model myopia (yes or no) predicted by tuition lessons in primary school, educational stream, father's education, and educational level, adjusted for confounders. The multivariate adjusted odds ratios for recruits with tuition lessons in primary school and gifted stream were 2.6 (95\% CI 1.4-4.9) and 3.8 (95\% CI 2.0-7.3) respectively. The odds ratio for one myopic parent versus none was 1.8 (95\% CI 0.8-3.8) and for two myopic parents versus none was 3.1 (95\% CI 1.0, 9.4). The odds ratio of parental myopia, adjusted for tuition lessons in primary school and educational stream, was 1.1 (95\% CI 0.6, 2.0).

The median age of onset of myopia was 10 years (primary four). The median age of onset of myopia for low myopes was 12 years compared with 9 years for high myopes $(\mathrm{p}<$ 0.001 ). The age of onset of myopia was lower in conscripts who reported having spent more time on close up work activity at age 7 years $(p=0.012)$, in the special/express/gifted stream $(\mathrm{p}=0.019)$, and recruits whose fathers 
$(\mathrm{p}=0.003)$ or mothers $(\mathrm{p}=0.004)$ had completed pre-university education (Table 5). In a logistic regression model based on the observed median age of myopia onset of 10 years, the odds ratio of early age of onset of myopia ( $<10$ years) for special/express/gifted stream was 2.4 (95\% CI 1.4-4.0) after adjusting for parental history of myopia and close up work activity at age 7 years. The odds ratio for close up work activity at 7 years was 1.5 (95\% CI 1.0-2.4), adjusting for parental history of myopia and educational stream. Father's and mother's educational level did not correlate with age of onset of myopia after adjustment for parental history of myopia and close up work activity.

\section{Discussion}

Education and educational variables correlated with myopia in Singapore military conscripts. Unlike many surveys of military populations with more restricted methodology, objective refraction and biometry data constituted the ocular measures. ${ }^{12}{ }^{13} \mathrm{~A}$ detailed questionnaire, designed specifically for this population, was administered individually to the recruits; such an approach to myopia risk factor assessment has been validated previously in the Singapore population. ${ }^{5}$ As typically observed, the conscripts in the present study with myopia had longer eyeballs, deeper vitreous chambers, deeper anterior chambers, and steeper corneas than the non-myopic subjects. ${ }^{15} 16$

The risk factor analysis revealed strong associations with education and factors related to education such as tuition lessons in primary school. A greater prevalence of myopia among more highly educated national servicemen has been observed in two previous prevalence studies in Singapore, but these reports did not quantify academic achievement, include the same breadth of other risk factors or provide biometry measurements as assessed here. ${ }^{12-14}$

Educational variables assessed here, possibly surrogates of intelligence, academic achievement, family income, or close up work activity, were associated with myopia. With the exception of close up work activity at age 7 year, a variable whose accuracy is difficult to ascertain, direct measures of close up work activity did not associate with myopia in this population. Associating reported close up work activity and myopia has generally proved difficult in previous epidemiological surveys as well, for reasons that remain obscure.$^{6-8}{ }^{17}$ In a study of elementary schoolchildren in Singapore, general near work scores did not correlate well with myopia progression. ${ }^{17}$ The progression rates of myopia increased after school examinations, but only in 7 year old myopes and non-myopes, and not in 9 or 12 year olds. This temporal offset of myopia progression rates and educational exposure highlights the complexity of establishing the role of close up work in myopia pathogenesis. Associations relating myopia and its severity to quantitative measures of current close up work activity in our study were weak. Perhaps, self reported close up work as assessed by questionnaire may not adequately address those features of close up activity important for myopia pathogenesis. Alternatively, other risk factors not assessed here or in other clinical assessments of close up activity, such as intelligence or academic achievement, may interact with or obscure the relation of myopia to self reported close up work activity. Possibly, close up work may not constitute a potent independent risk factor for myopia. However, the strong epidemiological associations of myopia with educational exposure on both individual and societal levels, with higher socioeconomic status and with advanced societal economic development all have made it difficult for investigators to reject the role of close up activity in myopia pathogenesis. For Singapore, in particular, the demanding educational system may produce a common high level of reading exposure with little variation in close up work activity in the population. Also, in our study of national servicemen, the weighted average of current close up work activity may not be as relevant a risk factor as previous close up activity at an earlier age when myopia developed and when exposure may have differed. Detailed quantitative estimates of past close up work at early ages may be difficult to measure accurately by retrospective methods owing to problems with recall.

While not precisely equivalent, educational exposure may be a surrogate measure for close up work activity. Tuition lessons in primary school involve additional class time comprised chiefly of reading and writing, along added homework; they may provide an index of early high levels of close up work activity. As tuition lessons in primary school but not in later years were associated with greater myopia, myopia susceptibility from educational activity and perhaps close up work may differ during the early school years and at later ages. The median age of onset of myopia among the subjects was 10 years; and thus, for the majority of recruits, early childhood risk factor exposures may be the most important.

Alternatively, tuition lessons in primary school, educational stream, or educational level may be indicators of socioeconomic status, academic achievement, intelligence, personality, or other possible risk factors for myopia, independent of close up work activity. Educational stream and years of education are markers of academic achievement, and recruits with tuition lessons in primary school may perform better in the year end school examinations. Moreover, academic achievement is often linked to intellectual ability; recruits with more advanced educational stream, years of education, and who had tuition lessons in primary school may have greater intellectual ability. Past epidemiological studies have evaluated the relation between academic achievement or intelligence with myopia. ${ }^{8}{ }^{18}$ Grosvenor noted that myopic children tend to come mainly from "high ability" classrooms in two schools where educational streaming was practised. ${ }^{18}$ Several studies have found that myopes score higher on tests of verbal intelligence and mental maturity. ${ }^{18}$

A larger proportion of myopes compared with non-myopes had one or two myopic 
parents. However, such simple associations do not resolve the ambiguities of whether shared genes or shared environment account for myopia trends within families. ${ }^{19}$ Because parental myopia status was obtained from the recruit questionnaire responses, potential errors in parental refractive classification may bias the familial myopia association and must qualify the interpretation of these data. None the less, environmental risks are further underscored by the $35 \%$ of myopic conscripts for whom neither parent was myopic. It is possible that a myopia gene(s) may determine ocular developmental response to particular environmental stimuli. If confirmed in other population studies, controls for environmental factors might be productively incorporated into genetic studies of myopia.

In conclusion, educational level, educational stream, and tuition lesions in primary school (all factors related to education) positively associated with myopia in military recruits. The positive correlations of educational stream and tuition lessons with myopia add evidence to the environmental or "use-abuse" theory for myopia. The role of close up visual activity as an independent risk factor remains indeterminate despite the detailed data obtained here.

Grant support: Defence Medical Research Institute (U86D-8 404-1-14)

We would like to thank Ms Bee-Fang Ng for performing the refractive measurements for the armed forces men. RAS is the recipient of a Research to Prevent Blindness physician-scientist merit award and received support from the Paul and Evanina Bell Mackall Foundation Trust.

\section{Appendix}

(Selected questions from the questionnaire)

1 Did you have tuition, either private or school (eg, remedial lessons) when you were in primary school? yes no

2 Did you have tuition, either private or school (eg, remedial lessons) when you were in secondary school? yes no

3 Educational stream gifted special express normal

4 At the age of 7 , how many hours per day did you usually spend on close up work activities such as reading and writing (outside school hours)? hours/day
1 Lin LK, Shih YF, Tsai CB, et al. Epidemiologic study of ocular refraction among schoolchildren in Taiwan in 1995. ocular refraction among schoolc
Optom Vis Sci 1999;76:275-81.

2 Lin LL, Chen CJ, Hung PT, et al. Nation-wide survey of myopia among schoolchildren in Taiwan, 1986. Acta Ophthalmol (Suppl) 1988;185:29-33.

3 Saw SM, Katz J, Schein OD, et al. Epidemiology of myopia. Epidem Reviews 1996;18:175-87.

4 Goss DA. Nearwork and myopia. Lancet 2000;356:1456-7.

5 Saw SM, Nieto FJ, Katz J, et al. Estimating the magnitude of close-up work in school-age children: a comparison of questionnaire and diary instruments. Ophthalmic Epidemiol 1999;6:291-301.

6 Richler A, Bear JC. Refraction, closeup work and education: a population study in Newfoundland. Acta Ophthalmol (Copenh) 1980;58:468-78.

7 Zylbermann R, Landau D, Berson D. The influence of study habits on myopia in Jewish teenagers. F Pediatr Ophthalmol Stabismus. 1993;30:319-22.

8 Teasdale TW, Goldschmidt E. Myopia and its relationship to education, intelligence and height: preliminary results from an on-going study of Danish draftees. Acta Ophthalmol (Suppl) 1988;185:41-3.

9 Rosner M, Belkin M. Intelligence, education, and myopia in males. Arch Ophthalmol 1987;55:302-8.

0 Parssinen TO. Relation between refraction, education, occupation, and age among 26 and 46 year old Finns. $A m \mathcal{F}$ Optom Physiol Opt 1987;64:136-43.

11 Wu HM, Yap EPH, Seet B, et al. Report on study of myopia and it impact in a cohort of $S A F$ enlistees. Singapore: Defence Medical Research Institute, 1998.

12 Chew SJ, Chia SC, Lee KH. The pattern of myopia in young Singaporean men. Singapore Med f 1988;29:201-11.

13 Au Eong KG, Tay TH, Lim MK. Race, culture and myopia in 110,236 young Singapore males. Singapore Med $\mathcal{F} 1993$; 34:29-32.

14 Au Eong KG, Tay TH, Lim MK. Education and myopia in 110,236 young Singaporean males. Singapore Med $\mathcal{F} 1993$; 34:489-92.

15 McBrien NA, Millodot M. A biometric investigation of late onset myopic eyes. Acta Ophthalmol 1987;65:461-8.

16 McBrien NA, Adams DW. A longitudinal investigation of adult-onset and adult-progression of myopia in an occupa-
tional group. Refractive and biometric findings. Invest Ophthalmol Vis Sci 1997;38:321-33.

17 Tan NW, Saw SM, Lam DS, et al. Temporal variations in myopia progression in Singaporean children within an academic year. Optom Vis Sci 2000;77:465-72.

18 Grosvenor $\mathrm{T}$. Refractive state, intelligence and refractive errors. Am $\mathscr{7}$ Optom Arch Am Acad Optom 1959;36:12-21.

19 Zadnik K, Satariano WA, Mutti DO, et al. The effect of parental history of myopia on children's eye size. $¥ A M A$ 1994;271:1323-7. 